\title{
Increased serum tumor necrosis factor receptor-associated factor-6 expression in patients with non-metastatic triple-negative breast cancer
}

\author{
CEMIL BILIR ${ }^{1}$, HUSEYIN ENGIN $^{2}$, MURAT CAN $^{3}$, SEVILI LIKHAN $^{2}$, \\ DERYA DEMIRTAS ${ }^{3}$, FATIH KUZU ${ }^{2}$ and TANER BAYRAKTAROGLU ${ }^{2}$ \\ ${ }^{1}$ Department of Internal Medicine, Division of Medical Oncology, Recep Tayyip Erdoğan University School of Medicine, \\ Rize 53020; Departments of ${ }^{2}$ Internal Medicine and ${ }^{3}$ Biochemistry, Bülent Ecevit University School of Medicine, \\ Kozlu, Zonguldak 67000, Turkey
}

Received May 21, 2014; Accepted March 9, 2015

DOI: $10.3892 / \mathrm{ol} .2015 .3094$

\begin{abstract}
Obesity appears to be associated with an increased risk of breast cancer (BC) and an inferior oncological outcome at the time of diagnosis, with poor outcomes most prominent in cases of triple-negative BC (TNBC). The present study analyzed serum tumor necrosis factor (TNF)-like weak inducer of apoptosis (TWEAK) and TNF receptor associated factor- 6 (TRAF) protein expression levels in 48 patients with non-metastatic $\mathrm{BC}$ and 26 obese control patients (without BC). The mean age of the cohort was 52.5 years (range, 35-78 years) and the patients had a median body mass index of $33.5 \mathrm{~kg} / \mathrm{m}^{2}$ (range, $30-47 \mathrm{~kg} / \mathrm{m}^{2}$ ). In the study population, $27.1 \%$ of $\mathrm{BC}$ patients were triple negative and $70.8 \%$ were hormone receptor (HR)-positive. Median serum TRAF6 expression was $0.90 \mathrm{ng} / \mathrm{ml}$ (range, $0.55-1.53 \mathrm{ng} / \mathrm{ml}$ ) in the $13 \mathrm{TNBC}$ patients and $0.63 \mathrm{ng} / \mathrm{ml}$ (range, $0.49-1.22 \mathrm{ng} / \mathrm{ml}$ ) in the 35 HR-positive BC patients; thus, TRAF6 expression was significantly higher in the TNBC patients compared with the obese control group ( 0.90 vs. $0.73 \mathrm{ng} / \mathrm{ml} ; \mathrm{P}=0.033)$. Furthermore, median serum TRAF6 expression levels were significantly higher in HR-negative patients compared with HR-positive patients ( 0.83 vs. $0.62 \mathrm{ng} / \mathrm{ml} ; \mathrm{P}=0.002)$. The present study demonstrated that serum TRAF6 expression levels were increased in TNBC and HR-negative patients with non-metastatic BC compared with HR- and human epidermal growth factor receptor 2-positive cases or the obese healthy
\end{abstract}

Correspondence to: Dr Cemil Bilir, Department of Internal Medicine, Division of Medical Oncology, Recep Tayyip Erdoğan University School of Medicine, 141145 Sokak, Sultan Orhan Mahalle, Rize 53020, Turkey

E-mail: cebilir@yahoo.com

Key words: breast cancer, triple negative, tumor necrosis factor receptor associated factor-6, tumor necrosis factor-like weak inducer of apoptosis, hormone receptor control group. Therefore, elevated TRAF6 expression may be a poor prognostic factor in non-metastatic BC. In addition, we propose that progesterone $(\mathrm{PR})$ negativity may be a more useful poor prognosis factor than estrogen receptor (ER) negativity, as TRAF6 expression levels were higher in the PR-negative patients compared with the ER-negative patients.

\section{Introduction}

Obesity has been associated with an increased risk of developing breast cancer (BC) and has been correlated with inferior oncological outcomes at the time of BC diagnosis (1). Majed et al (2) analyzed 19 years of follow-up data from a cohort of 14,709 patients with BC, and identified a significant association between obesity and distant recurrence for estrogen receptor (ER)-positive compared with ER-negative disease. However, only $30 \%$ of the cohort received adjuvant chemotherapy and not all patients were treated with endocrine therapy. Two subsequent studies provided consistent results: de Azambuja et al (3) reported worse outcomes for ER-positive compared with ER-negative disease; and Sestak et al (4) reported that postmenopausal women with ER-positive disease and high baseline body mass index (BMI) exhibited more distant recurrence. Furthermore, Sparano et al (5) reported the clinical outcomes from three clinical trials and determined that obese patients (BMI, $\geq 30 \mathrm{~kg} / \mathrm{m}^{2}$ ) had a significantly higher risk of recurrence and mortality. In addition, this was the first study to reveal that a poorer prognosis was associated with hormone receptor (HR)-positive and human epidermal growth factor receptor 2 (HER-2)-negative disease in obese patients with BC. Menopausal status was not defined in this study; however, a recent meta-analysis observed a poorer prognosis in obese patients with premenopausal TNBC compared with non-obese patients with BC, while no similar association was identified in postmenopausal women with TNBC (6).

Ongoing trials are investigating possible associations between obesity and poor prognosis in BC, etiopathogenesis and other malignancies. There are a number of theories regarding the association between obesity and $\mathrm{BC}$. One is 
that increased estrogen produced by adipocytes may trigger the growth of ER-positive mammary cells $(7,8)$. An alternative theory is that obesity and metabolic syndromes induce the production of insulin-like growth hormone, which has potent mitogenic activity on the epithelium (9). Finally, pro-inflammatory cytokines, such as interleukin-6 (IL-6) and tumor necrosis factor $\alpha(\mathrm{TNF} \alpha)$, which are synthesized by paracrine glands, may induce malignant phenotypes (10). However, these three possible mechanisms do not extensively clarify why specific subtypes of BC have poorer prognoses compared with others. In the current study, a number of inflammatory signaling pathways, such as the TNF pathway, were investigated. TNF-like weak inducer of apoptosis (TWEAK) is a member of the TNF superfamily originally identified in 1997, and is pivotal in various inflammatory conditions. Recent studies have identified TWEAK expression in human brain, lung, colon, liver and breast malignancies (11-14). Additionally, TNF receptor-associated factor (TRAF) proteins are involved in various intracellular signaling pathways. In particular, TRAF6 is an important E3 ubiquitin ligase that is involved in protein degradation $(15,16)$, with increased TRAF6 expression identified in the skeletal muscles of mice during atrophy (17). Therefore, we hypothesize that obesity may mask ongoing catabolism in obese patients with cancer. Additionally, it is known that obese patients with $\mathrm{BC}$ have poorer outcomes, particularly for HR-positive and HER-2-negative disease (5). Therefore, the aim of the present study was to investigate a possible association between various subtypes of $\mathrm{BC}$ and novel catabolic pathway parameters, such as serum TWEAK and TRAF6 expression levels.

\section{Patients and methods}

The present study cohort consisted of 74 patients (48 with non-metastatic BC and 26 obese controls) and was approved by the Bülent Ecevit University School of Medicine (Kozlu, Turkey) and Local Ethics Committees. The inclusion criteria were as follows: i) A diagnosis of histopathologically confirmed stage I-III BC, according to tumor-node-metastasis staging (18); ii) an Eastern Cooperative Oncology Group (ECOG) score (19) of 0-2; iii) an age of 18-80 years; iv) a BMI of $\geq 30 \mathrm{~kg} / \mathrm{m}^{2}$; and $\mathrm{v}$ ) eligibility to receive adjuvant chemotherapy. Furthermore, the exclusion criteria were as follows: i) refusal to consent to be included in the study; ii) chronic disease, such as hypertension, chronic heart disease, renal failure and thyroid disorders; and iii) an ECOG score of 3-4.

Pathological examination. Paraffin blocks were obtained from patients diagnosed with breast cancer and immunohistochemical (IHC) analysis for ER and PR expression was performed and scored based on staining intensity and the percentage of tumor cells with nuclear staining as well as Her-2 status. The results indicated that HER-2/neu status by fluorescence in situ hybridization (FISH) should be performed in all cases of breast tumour with a $2+$ score by IHC.

Patient characteristics. Patient height and weight were recorded. Subsequently, BMI was calculated as body weight divided by height squared $\left(\mathrm{kg} / \mathrm{m}^{2}\right)$. In addition, patients included in the present study were pathologically diagnosed with infiltrative ductal carcinoma, one of the most common subtypes recorded at Bülent Ecevit University School of Medicine. Written informed consent was obtained from the patients prior to the study according to institutional guidelines.

Blood samples were obtained from each subject prior to food consumption, between 8.00 a.m. and 9.00 a.m., following overnight bed rest. Routine biochemical parameters, such as glucose and hemoglobin concentration, were determined immediately after blood was drawn and plasma samples were stored at $-80^{\circ} \mathrm{C}$ until TWEAK and TRAF- 6 analysis was performed.

Serum expression levels of TWEAK and TRAF-6 were measured using commercially available ELISA kits from Cusabio (Wuhan, China). Data were analyzed using a label study with an ELx50 microplate washer and an ELx800 ELISA reader (BioTek Instruments, Inc., Winooski, VT, USA).

Statistical analyses. Descriptive and continuous variables are presented as the mean \pm standard deviation or the median (range). Categorical variables are presented as the relative frequency proportions and $95 \%$ confidence intervals. Disease-free survival, defined as the interval from the date of diagnosis to the date of progression or final follow-up visit, was calculated using the Kaplan-Meier method. In addition, appropriateness of data to normal ranges was controlled by the Shapiro-Wilk test. The data were analyzed using two-way analysis of variance and non-parametric tests. In all cases, $\mathrm{P}<0.05$ indicated a statistically significant difference and analyses were performed using the SPSS software package (version 17.0; SPSS, Inc., Chicago, IL, USA).

\section{Results}

The present study included 74 patients with a mean age of 52.5 years (range, 35-78 years) and a median BMI of $33.5 \mathrm{~kg} / \mathrm{m}^{2}$ (range, $30-47 \mathrm{~kg} / \mathrm{m}^{2}$ ). The cohort included 26 obese controls and 48 patients with diagnosed BC. The characteristics of the two groups are summarized and compared in Table I. There were no significant differences in the majority of the investigated parameters between the obese controls and obese patients with BC, including TWEAK and TRAF6 expression, baseline liver functions and hematological measurements. However, serum $\mathrm{C}$ reactive protein $(\mathrm{CRP})$ concentration was significantly higher in patients with $\mathrm{BC}$ compared with the obese controls $(\mathrm{P}<0.001)$.

The characteristics of the patients with $\mathrm{BC}$ are summarized in Table II. In the current study population, $27.1 \%$ of BC patients were triple negative and $70.8 \%$ were HR-positive (ER- and/or PR-positive). The majority of patients were classified with tumor stages T2-3 and or lymph node stage N0. Furthermore, $60 \%$ of the patients were postmenopausal. The median follow-up period was 15 months (range, 4-48 months) and no recurrence occurred during the follow-up period of the study.

ER status was negative in 23 patients and positive in 25 patients. According to the ER status, BMI was higher in ER-positive patients compared with ER-negative patients (36 vs. $31 \mathrm{~kg} / \mathrm{m}^{2}$; $\mathrm{P}=0.003$ ); however, there were no significant differences in median TWEAK and TRAF6 expression 
Table I. Comparison of characteristics between the control group $(n=26)$ and the patients with BC $(n=48)$.

\begin{tabular}{|c|c|c|c|}
\hline Characteristic & Control group, $\mathrm{n}( \pm \mathrm{SD} /$ range $)$ & $\mathrm{BC}$ group, n (SD/range) & P-value \\
\hline Age, years & $52.00( \pm 11)$ & $53.00( \pm 10)$ & 0.850 \\
\hline $\mathrm{BMI}, \mathrm{kg} / \mathrm{m}^{2}$ & $36.30( \pm 5.0)$ & $34.40( \pm 3.9)$ & 0.120 \\
\hline Glucose, mg/dl & $99.00( \pm 11)$ & $105.00( \pm 16)$ & 0.230 \\
\hline Hemoglobin, g/dl & $12.70( \pm 0.9)$ & $12.40( \pm 1.4)$ & 0.950 \\
\hline Creatinine, mg/dl & $1.00( \pm 0.3)$ & $0.93( \pm 0.15)$ & 0.790 \\
\hline Albumin, g/dl & $4.00( \pm 0.45)$ & $4.40( \pm 0.3)$ & 0.850 \\
\hline $\mathrm{WBC}, \mathrm{mm}^{3}$ & $7200.00( \pm 1900)$ & $8100.00( \pm 1600)$ & 0.064 \\
\hline $\mathrm{CRP}, \mathrm{mg} / \mathrm{dl}$ & $2.00(1-5)$ & $3.00(1-23)$ & $<0.001$ \\
\hline AST, IU/1 & $21.00(14-74)$ & $20.00(13-64)$ & 0.590 \\
\hline ALT, IU/1 & $13.00(5-62)$ & $17.00(8-102)$ & 0.160 \\
\hline TWEAK, pg/ml & $723.00(400-1010)$ & $649.00(380-1451)$ & 0.170 \\
\hline TRAF6, ng/ml & $0.73(0.5-1.14)$ & $0.70(0.49-1.53)$ & 0.320 \\
\hline
\end{tabular}

BC, breast cancer; SD, standard deviation; BMI, body mass index; WBC, white blood count; CRP, C reactive protein; AST, aspartate aminotransferase; ALT, alanine aminotransferase; TWEAK, tumor necrosis factor-related weak inducer of apoptosis; TRAF, tumor necrosis factor receptor-associated factor.

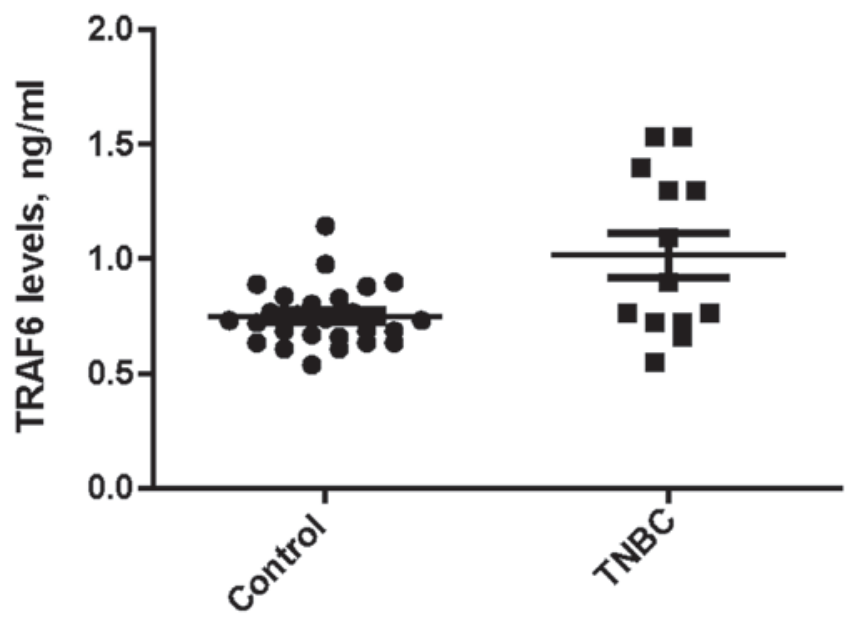

Figure 1. Comparison of median serum TRAF6 expression levels between the obese control subjects and TNBC patients. TRAF6, tumor necrosis factor receptor-associated factor 6 ; TNBC, triple-negative breast cancer.

levels, CRP concentration or menopausal status $(\mathrm{P}=0.960$, $\mathrm{P}=0.090, \mathrm{P}=0.240$ and $\mathrm{P}=0.260$, respectively). $\mathrm{PR}$ status was negative in 17 patients and positive in 31 patients, with BMI significantly higher in PR-positive patients compared with PR-negative patients (36 vs. $32 \mathrm{~kg} / \mathrm{m}^{2} ; \mathrm{P}=0.013$ ). Furthermore, the median expression levels of serum TRAF6 were $0.90 \mathrm{ng} / \mathrm{ml}$ (range, $0.55-1.53 \mathrm{ng} / \mathrm{ml}$ ) in PR-negative and $0.61 \mathrm{ng} / \mathrm{ml}$ (range, $0.49-1.40 \mathrm{ng} / \mathrm{ml}$ ) in PR-positive patients; this difference was statistically significant $(\mathrm{P}<0.001)$. According to the serum TWEAK expression levels, CRP concentration and menopausal status, there were no statistically significant differences between PR-positive and PR-negative patients $(\mathrm{P}=0.800$, $\mathrm{P}=0.580$ and $\mathrm{P}=0.160$, respectively).

The median serum TRAF6 expression levels were $0.90 \mathrm{ng} / \mathrm{ml}$ (range, $0.55-1.53 \mathrm{ng} / \mathrm{ml}$ ) in the $13 \mathrm{TNBC}$ patients and $0.63 \mathrm{ng} / \mathrm{ml}$ (range, $0.49-1.22 \mathrm{ng} / \mathrm{ml}$ ) in the $35 \mathrm{HR}$-positive BC

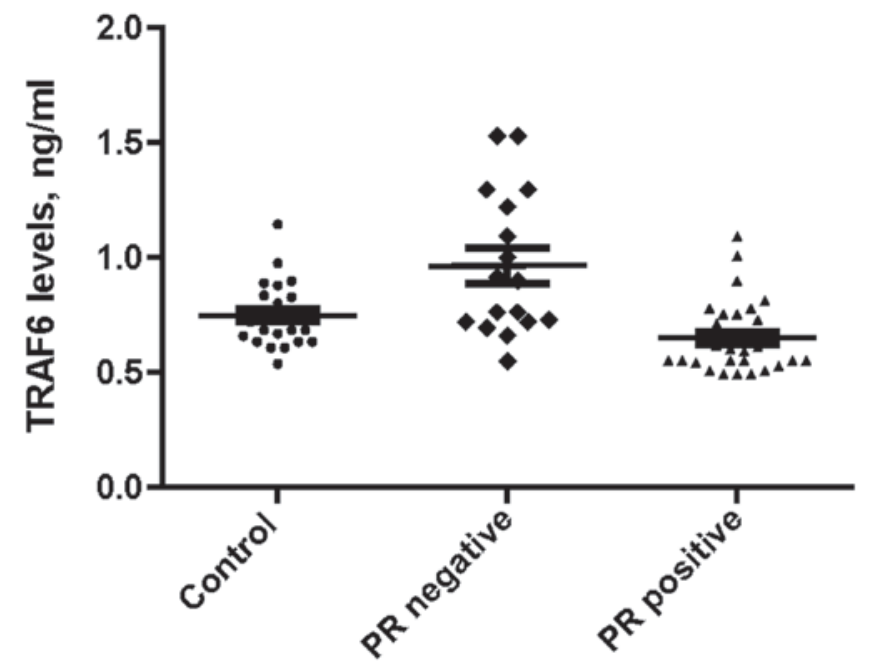

Figure 2. Comparison of median serum TRAF6 expression levels between the obese control subjects, and PR-negative and -positive patients. TRAF6, tumor necrosis factor receptor-associated factor 6; PR, progesterone receptor.

patients. This difference was statistically significant $(\mathrm{P}=0.010)$. However, there were no significant differences in the median expression levels of serum TWEAK, CRP concentration, $\mathrm{BMI}$ and menopausal status $(\mathrm{P}=0.580, \mathrm{P}=0.490, \mathrm{P}=0.070$ and $\mathrm{P}=0.220$, respectively) between the TNBC and HR-positive patients. HR expression was negative in 14 patients and positive in 34 patients. Median serum TRAF6 expression levels were significantly higher in HR-negative patients compared with HR-positive patients ( 0.83 vs. $0.62 \mathrm{ng} / \mathrm{ml} ; \mathrm{P}=0.002)$. By contrast, BMI was significantly higher in HR-positive patients compared with HR-negative patients (36 vs. $31.5 \mathrm{~kg} / \mathrm{m}^{2}$; $\mathrm{P}=0.005)$. Additionally, there were no significant differences between the groups according to the median serum TWEAK expression levels, CRP concentration and menopausal status ( $\mathrm{P}=0.400, \mathrm{P}=0.600$ and $\mathrm{P}=0.350$, respectively). 
Table II. Characteristics of patients with breast cancer.

\begin{tabular}{|c|c|}
\hline Characteristic & Frequency, n (\% \\
\hline \multicolumn{2}{|l|}{ Estrogen receptor } \\
\hline Positive & $25(52.1)$ \\
\hline Negative & $23(47.9)$ \\
\hline \multicolumn{2}{|c|}{ Progesterone receptor } \\
\hline Positive & $31(64.6)$ \\
\hline Negative & $17(35.4)$ \\
\hline \multicolumn{2}{|l|}{ Hormone receptor } \\
\hline Positive & $35(70.8)$ \\
\hline Negative & $13(29.2)$ \\
\hline \multicolumn{2}{|l|}{ HER-2 } \\
\hline Positive & $35(70.8)$ \\
\hline Negative & $13(29.2)$ \\
\hline Triple negative & $13(27.1)$ \\
\hline \multicolumn{2}{|l|}{ TNM stage } \\
\hline $\mathrm{T} 1$ & $9(18.8)$ \\
\hline $\mathrm{T} 2$ & $15(31.3)$ \\
\hline $\mathrm{T} 3$ & $24(50.0)$ \\
\hline $\mathrm{T} 4$ & $0(0.0)$ \\
\hline NO & $28(58.3)$ \\
\hline $\mathrm{N} 1$ & $8(16.7)$ \\
\hline $\mathrm{N} 2$ & $6(12.5)$ \\
\hline N3 & $6(12.5)$ \\
\hline M0 & $48(100.0)$ \\
\hline I & $30(62.5)$ \\
\hline II & $11(22.9)$ \\
\hline III & $7(14.6)$ \\
\hline \multicolumn{2}{|l|}{ Menopausal status } \\
\hline Premenopausal & $19(39.6)$ \\
\hline Postmenopausal & $29(60.4)$ \\
\hline
\end{tabular}

TNM, tumor-node-metastasis; HER-2, human epidermal growth factor receptor 2 .

Median serum TRAF6 expression levels were significantly higher in the TNBC group compared with the obese control group ( 0.90 vs. $0.73 \mathrm{ng} / \mathrm{ml} ; \mathrm{P}=0.033$ ), as indicated in Fig. 1 . Additionally, there was a similar difference in median serum TRAF6 expression levels between the PR-negative and obese control groups ( 0.92 vs. $0.72 \mathrm{ng} / \mathrm{ml} ; \mathrm{P}=0.023)$, as indicated in Fig. 2.

\section{Discussion}

In the present study, TRAF6, which is central in the regulation of TNF pathway functions, was demonstrated to exhibit increased expression levels in TNBC and HR-negative non-metastatic BC patients compared with HR-positive and HER-2-positive patients or the obese control group. Excluding TRAF6 expression levels, no significant differences were identified in the serum TWEAK, CRP and biochemical parameters between any hormonal or HER-2 status of BC.
In a healthy population, body muscle mass is sustained by physical activity and nutritional status, with an ongoing balance between protein degradation and synthesis. If one of these processes becomes dominant, muscle hypertrophy or atrophy will result. Small changes in protein synthesis or degradation may cause large protein deficits and continuous protein turnover. However, obesity can mask these vitally important catabolic changes in healthy individuals and cancer patients, even if the individual has progressed to cachexia $(20,21)$. Inflammatory-associated signaling pathways may limit muscle protein synthesis via numerous mechanisms (20). For example, $\mathrm{TNF} \alpha$ is able to activate the transcription factor nuclear factor $\kappa \mathrm{B}(\mathrm{NF}-\kappa \mathrm{B})$, a molecule that inhibits the synthesis of the muscle-specific transcription factor MyoD, as well as cellular differentiation (22). In addition, members of the TGF- $\beta$ family induce muscle wasting downstream of mothers against decapentaplegic activation (23). Finally, IL-6 activates signaling by binding to ligand-specific receptors, in soluble or membrane-bound forms, to induce the signal transducers and activators of transcription-1 and -3 (STAT1/3), extracellular signal-regulated kinase (ERK) and phosphatidylinositol 3-kinase (PI3K)/Akt signaling pathways (20,24,25). It is well known that the ERK pathway has a function in cancer cachexia and muscle wasting (26). In addition, the central role of the ubiquitin proteasome proteolysis pathway in muscle atrophy has been demonstrated in various animal models (27-29).

TRAF6 is an important E3 ubiquitin ligase that targets proteins for degradation (30). In a number of previous studies, it was determined that TRAF6 may activate the NF- $\kappa$ B, MAPK and PI3K/Akt signaling pathways $(31,32)$. In addition, increased TRAF6 expression and autoubiquitination were observed in the skeletal muscle of mice during atrophy (17). To the best of our knowledge, the current study is the first to measure serum TRAF6 and TWEAK expression levels in patients with BC. TRAF6 expression levels were significantly higher in TNBC and HR-negative patients with BC compared with the obese control subjects. These elevated TRAF expression levels may be a marker of upcoming catabolism in BC patients, particularly in those with specific BC subtypes. Yamamoto et al (33) reported that $\mathrm{NF}-\kappa \mathrm{B}$-inducing kinase (NIK) is highly expressed in basal-like (ER-, PR- or HER-2-negative) subtypes of BC specimens and cell cultures. Thus, the study proposed that suppressing NIK expression may be a potential treatment strategy for patients with TNBC. The current findings are consistent with this result, as TRAF6 has a regulatory function in the NF- $\kappa \mathrm{B}$ signaling pathway. To date, it is unknown why TRAF6 expression levels are higher in TNBC and HR-negative patients; however, it may be associated with the numerous signaling pathways involved in $\mathrm{BC}$, including the PI3K/Akt pathway. The PI3K/Akt signaling pathway has an important prognostic role in the luminal type of BC. Furthermore, Arsenic et al (34) recently demonstrated that PI3K catalytic subunit $\alpha$ mutations are more frequent in HR-positive/HER-2-negative patients and that the H1047R mutation in particular resulted in worse outcomes. Therefore, it is possible that luminal types of BC may be affected by factors that have yet to be identified.

No significant differences were found in the serum TWEAK expression levels between BC subtypes. Previous studies have indicated that the interaction between TWEAK and its 
receptor (fibroblast growth factor-inducible 14) causes cell proliferation, differentiation, migration, apoptosis, inflammation, angiogenesis and malignancies in various organs, such as the lungs, brain, liver, pancreas, breast and esophagus $(35,36)$. Chao et al (37) demonstrated that the TWEAK receptor was highly expressed in all subtypes of invasive ductal breast carcinoma. In an alternative study, TWEAK mRNA expression levels were not significantly different between lean and obese subjects. However, TWEAK receptor expression was only quantifiable in subjects with a BMI of $>38 \mathrm{~kg} / \mathrm{m}^{2}$ (38). In the present study, no significant difference in the serum TWEAK expression levels was identified between obese control and BC patients. However, the total current study population was not severely obese $\left(>38 \mathrm{~kg} / \mathrm{m}^{2}\right)$ and TWEAK mRNA expression determined from tissue samples may not reflect its expression in plasma.

To date, there is no proven targeted therapy for the treatment of patients with TNBC; however, TRAF6 may be a good target in this population. The NF- $\mathrm{KB}$ signaling pathway is activated by TRAF6 (39), and certain targeted therapies against the pathway have been studied to determine their efficacy. For example, in a study investigating multiple myeloma, bortezomib treatment was observed to downregulate TRAF6 expression at the protein and mRNA levels, resulting in a reduction in osteoclast formation (40). Similarly, Tseng et al (41) investigated the efficacy of bortezomib treatment in vitro and identified that TNBC cells were sensitive to its cytotoxic activity. The aforementioned data supports the results of the current study; therefore, it is proposed that elevated TRAF6 may be a novel therapeutic target for patients with TNBC. In addition, combining a targeted therapy with systemic chemotherapy may reduce the poor prognosis of patients with TNBC. Furthermore, we hypothesize that PR negativity may be a more useful marker of a poor prognosis compared with ER negativity, as TRAF6 expression levels are higher in PR-negative patients compared with ER-negative patients.

There were a number of limitations to the present study. For example, due to the short follow-up period, the association between TRAF6 expression levels, and the overall survival of TNBC and non-TNBC patients could not be established. However, despite the limited number of patients (13 TNBC and 35 non-TNBC patients) and the preliminary nature of the current study, TRAF6 expression levels were identified as a possible prognostic factor in TNBC patients. Furthermore, due to the limited number of ELISA kits available, only an obese healthy control was selected rather than using non-obese and obese healthy control groups.

In conclusion, elevated TRAF6 expression levels may indicate a poor prognosis in patients with $\mathrm{BC}$, particularly in triple-negative and HR-negative patient subtypes. Furthermore, therapies targeted to the PI3K-Akt and NF- $\kappa \mathrm{B}$ signaling pathways may be more effective in the treatment of TNBC patients with elevated TRAF6 expression levels at the time of diagnosis.

\section{References}

1. Rose DP, Gilhooly EM and Nixon DW: Adverse effects of obesity on breast cancer prognosis and the biological actions of leptin (Review). Int J Oncol 21: 1285-1292, 2002.

2. Majed B, Moreau T, Senouci K, et al: Is obesity an independent prognosis factor in woman breast cancer? Breast Cancer Res Treat 111: 329-342, 2008
3. de Azambuja E, McCaskill-Stevens W, Francis P, et al: The effect of body mass index on overall and disease-free survival in node-positive breast cancer patients treated with docetaxel and doxorubicincontaining adjuvant chemotherapy: The experience of the BIG 02-98 trial. Breast Cancer Res Treat 119: 145-53, 2010.

4. Sestak I, Distler W, Forbes JF, et al: Effect of body mass index on recurrences in tamoxifen and anastrozole treated women: an exploratory analysis from the ATAC trial. J Clin Oncol 28: 3411-3415, 2010.

5. Sparano JA, Wang M, Zhao F, et al: Obesity at diagnosis is associated with inferior outcomes in hormone receptor-positive operable breast cancer. Cancer 118: 5937-5946, 2012.

6. Pierobon $M$ and Frankenfeld CL: Obesity as a risk factor for triple-negative breast cancers: a systematic review and meta-analysis. Breast Cancer Res Treat 137: 307-314, 2013.

7. Vona-Davis L and Rose DP: Adipokines as endocrine, paracrine and autocrine factors in breast cancer risk and progression. Endocr Relat Cancer 14: 189-206, 2007.

8. Schäffler A, Schölmerich J and Buechler C: Mechanisms of disease: adipokines and breast cancer - endocrine and paracrine mechanisms that connect adiposity and breast cancer. Nat Clin Pract Endocrinol Metab 3: 345-354, 2007.

9. Stephenson GD and Rose DP: Breast cancer and obesity: an update. Nutr Cancer 45: 1-16, 2003.

10. Weichhaus M, Broom I and Bermano G: The molecular contribution of TNF- $\alpha$ in the link between obesity and breast cancer. Oncol Rep 25: 477-483, 2011

11. Chicheportiche Y, Bourdon PR, Xu H, et al: TWEAK, a new secreted ligand in the tumor necrosis factor family that weakly induces apoptosis. J Biol Chem 272: 32401-32410, 1997.

12. Winkles JA: The TWEAK-Fn14 cytokine-receptor axis: discovery, biology and therapeutic targeting. Nat Rev Drug Discov 7: 411-425, 2008.

13. Kawakita T, Shiraki K, Yamanaka Y, et al: Functional expression of TWEAK in human colonic adenocarcinoma cells. Int J Oncol 26: 87-93, 2005.

14. Kawakita T, Shiraki K, Yamanaka Y, et al: Functional expression of TWEAK in human hepatocellular carcinoma: possible implication in cell proliferation and tumor angiogenesis. Biochem Biophys Res Commun 318: 726-733, 2004.

15. Pickart CM: Mechanisms underlying ubiquitination. Annu Rev Biochem 70: 503-533, 2001.

16. Mukhopadhyay D and Riezman H: Proteasome-independent functions of ubiquitin in endocytosis and signaling. Science 315: 201-205, 2007.

17. Paul PK, Gupta SK, Bhatnagar S, et al: Targeted ablation of TRAF6 inhibits skeletal muscle wasting in mice. J Cell Biol 191: 1395-1411, 2010.

18. Tavassoli FA and Devilee P (eds): Tumours of the breast. In: World Health Organization Classification of Tumours. Pathology and Genetics of Tumours of the Breast and Female Genital Organs. IARC Press, Lyon, pp13-59, 2003.

19. Oken MM, Creech RH, Tormey DC, et al: Toxicity and response criteria of the Eastern Cooperative Oncology Group. Am J Clin Oncol 5: 649-655, 1982.

20. Johns N, Stephens NA and Preston T: Muscle protein kinetics in cancer cachexia. Curr Opin Support Palliat Care 6: 417-423,2012.

21. Cohen S, Brault JJ, Gygi SP, et al: During muscle atrophy, thick, but not thin, filament components are degraded by MuRF1-dependent ubiquitylation. J Cell Biol 185: 1083-1095, 2009.

22. Acharyya S and Guttridge DC: Cancer cachexia signaling pathways continue to emerge yet much still points to the proteasome. Clin Cancer Res 13: 1356-1361, 2007.

23. Lee SJ and Glass DJ: Treating cancer cachexia to treat cancer. Skelet Muscle 1: 2, 2011.

24. Fischer P and Hilfiker-Kleiner D: Survival pathways in hypertrophy and heart failure: the gp130-STAT3 axis. Basic Res Cardiol 102: 279-297, 2007.

25. Jones SA, Scheller J and Rose-John S: Therapeutic strategies for the clinical blockade of IL-6/gp130 signaling. J Clin Invest 121: 3375-3383, 2011.

26. Penna F, Costamagna D, Fanzani A, Bonelli G, Baccino FM and Costelli P: Muscle wasting and impaired myogenesis in tumor bearing mice are prevented by ERK inhibition. PLoS One 5: 13604, 2010.

27. Jagoe RT and Goldberg AL: What do we really know about the ubiquitin-proteasome pathway in muscle atrophy? Curr Opin Clin Nutr Metab Care 4: 183-190, 2001.

28. Lecker SH, Solomon V, Mitch WE and Goldberg AL: Muscle protein breakdown and the critical role of the ubiquitin-proteasome pathway in normal and disease states. J Nutr (Suppl) 129: 227S-237S, 1999. 
29. Bodine SC, Latres E, Baumhueter S, et al: Identification of ubiquitin ligases required for skeletal muscle atrophy. Science 294: 1704-1708, 2001.

30. Pickart CM: Mechanisms underlying ubiquitination. Annu Rev Biochem 70: 503-533, 2001.

31. Yang WL, Wang J, Chan $\mathrm{CH}$, et al: The E3 ligase TRAF6 regulates Akt ubiquitination and activation. Science 325: 1134-1138, 2009.

32. Yamashita M, Fatyol K, Jin C, Wang X, Liu Z and Zhang YE: TRAF6 mediates Smad-independent activation of JNK and p38 by TGF-beta. Mol Cell 31: 918-924, 2008.

33. Yamamoto M, Ito T, Shimizu T, et al: Epigenetic alteration of the NF- $\mathrm{kB}$-inducing kinase (NIK) gene is involved in enhanced NIK expression in basal-like breast cancer. Cancer Sci 101: 2391-2397, 2010.

34. Arsenic R, Lehmann A, Budczies J, et al: Analysis of PIK3CA mutations in breast cancer subtypes. Appl Immunohistochem Mol Morphol 22: 50-56, 2014.

35. Polek TC, Talpaz M, Darnay BG and Spivak-Kroizman T: TWEAK mediates signal transduction and differentiation of RAW264.7 cells in the absence of Fn14/TweakR. Evidence for a second TWEAK receptor. J Biol Chem 278: 32317-32323, 2003.
36. Yoriki R, Akashi S, Sho M, et al: Therapeutic potential of the TWEAK/Fn 14 pathway in intractable gastrointestinal cancer. Exp Ther Med 2: 103-108, 2011.

37. Chao DT, Su M, Tanlimco S, et al: Expression of TweakR in breast cancer and preclinical activity of enavatuzumab, a humanized anti-TweakR mAb. J Cancer Res Clin Oncol 139: 315-325, 2013.

38. Chacón MR, Richart C, Gómez JM, et al: Expression of TWEAK and its receptor Fn14 in human subcutaneous adipose tissue. Relationship with other inflammatory cytokines in obesity. Cytokine 33: 129-137, 2006.

39. Liu H, Tamashiro S, Baritaki S, et al: TRAF6 activation in multiple myeloma: a potential therapeutic target. Clin Lymphoma Myeloma Leuk 12: 155-163, 2012.

40. Hongming $\mathrm{H}$ and Jian $\mathrm{H}$ : Bortezomib inhibits maturation and function of osteoclasts from PBMCs of patients with multiple myeloma by downregulating TRAF6. Leuk Res 33: 115-122, 2009.

41. Tseng LM, Liu CY, Chang KC, Chu PY, Shiau CW and Chen KF: CIP2A is a target of bortezomib in human triple negative breast cancer cells. Breast Cancer Res 14: R68, 2012. 